\title{
Accuracy of a new method for semi-quantitative assessment of right ventricular ejection fraction by cardiac MRI: right ventricular fractional diameter changes
}

Emmanuelle Vermes, Nicolas Rebotier, Olivier Genee, Julien Pucheux, Anne Delhommais, Daniel Alison

From 16th Annual SCMR Scientific Sessions

San Francisco, CA, USA. 31 January - 3 February 2013

\section{Background}

Cardiovascular magnetic resonance (CMR) is the gold standard to measure right ventricular ejection fraction (RVEF). Longitudinal shortening is historically known to be the predominant part of its global systolic function and less attention has been paid to the transversal contraction. The aim of this study was to evaluate RV transverse motion in a large cohort of patients referred for CMR and assess its relationship with RVEF.

\section{Methods}

We retrospectively analyzed the CMR scans of 300 consecutive patients referred for CMR between January and December 2010. Reference RV ejection fraction was determined from short axis sequences using the volumetric method. Transverse parameters called RV fractional diameter changes (FDC) were calculated after measuring RV diastolic (D) and systolic (S) diameters at basal and medium level in short axis view (respectively FBDC and FMDC) $\mathrm{FBDC}=100 \times(\mathrm{D}-\mathrm{S}) / \mathrm{D}$ (Figure: $\mathrm{FBDC}=100$ $\mathrm{x}(51.32-33.20) / 51.32=35.7 \%)$.We also measured the tricuspid annular plane systolic excursion (TAPSE) in the four chambers view as a longitudinal reference.

\section{Results}

Population was divided into 2 groups according RVEF, 250 patients had a preserved RVEF (>40\%) and 50 had a RV dysfunction (RVEF $\leq 40 \%$ ). Both transverse and longitudinal motions were significantly reduced in the group with RV dysfunction ( $\mathrm{p}<.0001)$. After ROC analysis, areas under the curve for FBDC,FMDC and TAPSE, were respectively $0.79,0.82$ and 0.72 with the highest sensitivity and specifi-

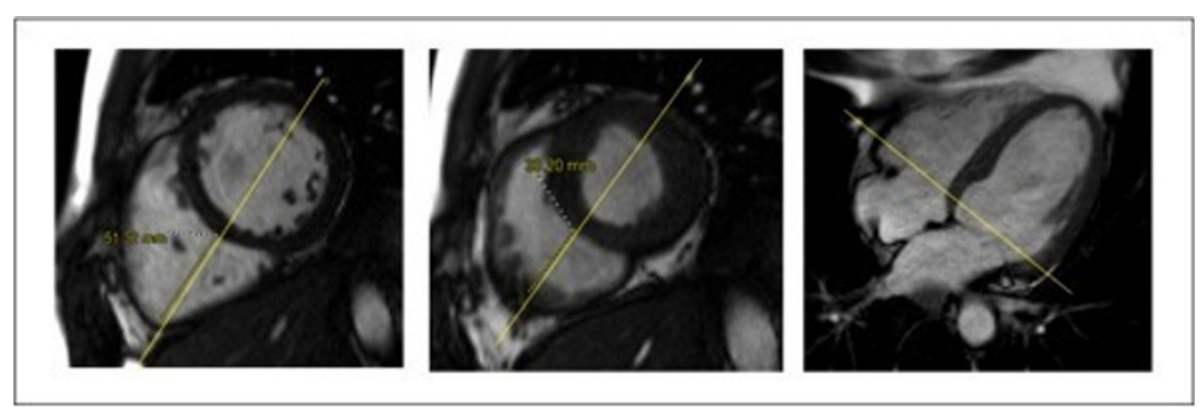

Figure 1

University Hospital of Tours, Chambray les Tours, France

() 2013 Vermes et al; licensee BioMed Central Ltd. This is an Open Access article distributed under the terms of the Creative Commons 
city of $68 \%$ and $88 \%$ for FMDC ( threshold at $19.9 \%$ ) to predict RVEF. FMDC had an excellent negative predictive value of $93 \%$.

\section{Conclusions}

Right ventricular fractional diameter changes, especially at the medium level, appear to be accurate for semi quantitative assessment of RV function by CMR.

\section{Funding}

No funding.

Published: 30 January 2013

doi:10.1186/1532-429X-15-S1-E80

Cite this article as: Vermes et al:: Accuracy of a new method for semiquantitative assessment of right ventricular ejection fraction by cardiac

MRI: right ventricular fractional diameter changes. Journal of

Cardiovascular Magnetic Resonance 2013 15(Suppl 1):E80.

Submit your next manuscript to BioMed Central and take full advantage of:

- Convenient online submission

- Thorough peer review

- No space constraints or color figure charges

- Immediate publication on acceptance

- Inclusion in PubMed, CAS, Scopus and Google Scholar

- Research which is freely available for redistribution

Submit your manuscript at www.biomedcentral.com/submit 